We developed an in vitro organ bath method to measure permeability and contractility simultaneously in murine intestinal segments. To investigate whether permeability and contractility are correlated and influenced by mucosal damage owing to inflammation, BALB/c mice were exposed to a $10 \%$ dextran sulphate sodium (DSS) solution for 8 days to induce colitis. The effect of pharmacologically induced smooth muscle relaxation and contraction on permeability was tested in vitro. Regional permeability differences were observed in both control and $10 \%$ DSS-treated mice. Distal colon segments were less permeable to ${ }^{3} \mathrm{H}$-m an nitol and ${ }^{14} \mathrm{C}$-PEG 400 molecules compared with proximal colon and ileum. In testinal permeability in control vs. $10 \%$ DSS mice was not altered, although histologic inflammation score and IFN- $\gamma$ pro-inflammatory cytokine levels were significantly increased in proximal and distal colon. IL$1 \beta$ levels were enhanced in these proximal and distal segments, but not significantly different from controls. Any effect of pharmacologically induced contractility on intestinal permeability could not be observed. In conclusion, intestinal permeability and contractility are not correlated in this model of experimentally induced colitis in mice. Although simultaneous measurement in a physiological set-up is possible, this method has to be further validated.

Key words: permeability, contractile activity, dextran induced colitis, mannitol, polyethylene glycol 400, mice

\section{Intestinal permeability and contractility in murine colitis}

\author{
M. E. van Meeteren, ${ }^{1, C A}$ J. D. van Bergeijk, ${ }^{2}$ \\ A. P. M. van Dijk, ${ }^{1}$ C. J. A. M. Tak, ${ }^{1}$ \\ M. A. C. Meijssen ${ }^{2}$ and F. J. Zjistra'
}

\begin{abstract}
${ }^{1}$ Department of Pharmacology, Erasmus University Rotterdam, Dr. Molewaterplein 50, 3015 GJ

Rotterdam, and ${ }^{2}$ Department of Gastroenterology, University Hospital Dijkzigt Rotterdam, The Netherlands
\end{abstract}

\footnotetext{
${ }^{\mathrm{CA}}$ Corresponding Author

Tel: $(+31) 104087544$

Fax: $(+31) 104366839$
}

\section{Introduction}

The intestinal epithelium demonstrates different properties, providing both barrier and transport functions to luminal molecules. A defective barrier function may contribute to changes in intestinal permeability. As a result of this impaired barrier function, antigen access can initiate and perpetuate inflammation. ${ }^{1}$ Moreover, studies in animal models indicate a causal relationship between the presence of mucosal inflammation and altered sensory-motor function. ${ }^{2}$ In human inflammatory bowel disease (IBD) alterations in intestinal permeability ${ }^{3}$ and motility $^{2,4}$ are both reported. However, it remains unclear whether these factors play an initiating role in the pathogenesis of human IBD or are secondary results of released inflammatory mediators.

In clinical practice and research, several intestinal permeability tests are used. Monitoring urinary excretion of orally administered test markers provides information on the intestinal barrier function. Frequently used markers are the cylindrical polymer polyethylene glycol 400 (PEG 400$)^{5}$ with a crosssectional diameter of $5.3 \AA$, the globular shaped sugar alcohol mannitol ${ }^{6}$ with a cross-sectional diameter of

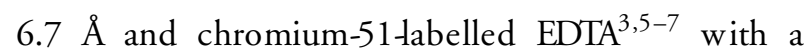
cross-sectional diameter of approximately $11 \AA \AA^{8,9}$

Current in vitro animal studies of intestinal permeability use flat tissue sheets, mounted in Ussing chambers,${ }^{10}$ while contractility is studied in smooth muscle strips immersed in organ baths. ${ }^{11}$ Intestinal permeability in in vivo animal models is mostly studied in perfused intestinal segments, ${ }^{12}$ giving a more physiological approach. However, operational systems to study intestinal permeability and contractility simultaneously in whole colonic segments, including the mucosa, longitudinal and circular layers and neuronal plexus are not available. Therefore our aim was to develop an in vitro organ bath method to measure permeability and contractility simultaneously in normal and inflamed intestinal segments of mice. The degree of inflammation was determined by macroscopic scoring, histology and measuring cytokine levels in different intestinal segments.

\section{Methods}

\section{Animals}

Female BALB/c mice (20-22 g, IFFA Credo, France) were used in this study. They were kept individually 
on chopped wood bedding in polystyrene cages under a 12 h day/night cycle at $20-22^{\circ} \mathrm{C}$, and with a relative humidity of $50 \%$ Mice were permitted free access to a standard mouse chow (Hope Farms, Woerden, The Netherlands) and DSS-supplemented or normal tap water.

The experiments were carried out after approval of the Ethics Committee for the use of experimental animals of the Rotterdam University Hospital (protocol 118-97-01).

\section{Experimental design}

Colitis was induced by adding $10 \%(\mathrm{wt} / \mathrm{vol})$ DSS $(\mathrm{Mw}>500$ 000, Pharmacia Biotech AB, Uppsala, Sweden) to the drinking water for 8 days. The control group received normal tap water throughout the study. At day 7 all animals were deprived from food overnight and killed by cervical dislocation on day 8 . Prior to study initiation and before deprivation, body weight was measured.

\section{Drugs}

Sodium nitroprusside $(0.1 \mathrm{M})$ and carbachol $(0.1 \mathrm{M})$ both from Sigma (St Louis, MO, USA) were dissolved in distilled water and stored at $4^{\circ} \mathrm{C}$ until use.

\section{Tissue preparation}

Upon sacrifice, the intestines were removed from the abdominal cavity. A segment of ileum most proximal to the caecum and a proximal and distal colon segment were taken and immediately immersed in standard Krebs buffer ( $\mathrm{pH} 7.4$ ) containing in $\mathrm{mmol} / \mathrm{l}$ : $118 \mathrm{NaCl}, 4.7 \mathrm{KCI}, 2.5 \mathrm{CaCl}_{2} .2 \mathrm{H}_{2} \mathrm{O}, 1.2 \mathrm{MgSO}_{4} .7 \mathrm{H}_{2} \mathrm{O}$,

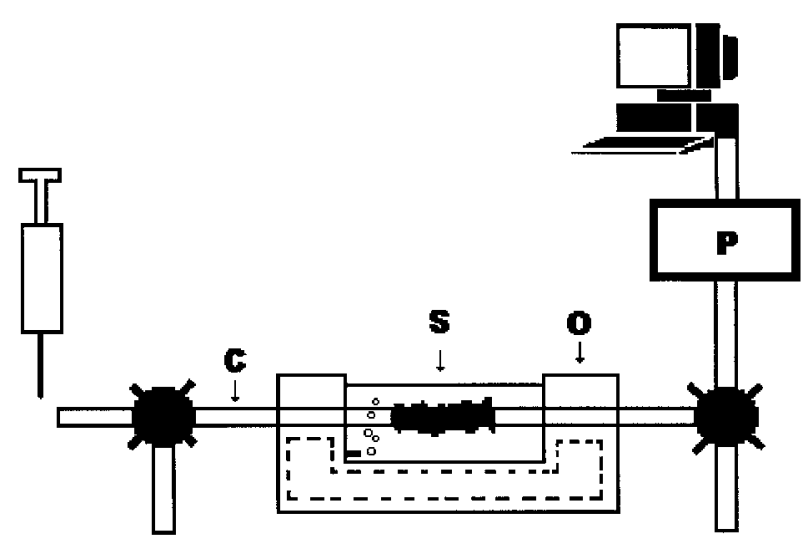

FIG. 1. Schematic presentation of the in vitro model. The intestinal segment (S) is cannulated with stainless-steel cannulas (C) and mounted in a double-walled organ bath (O) that contains carbogenated standard Krebs buffer at $37^{\circ} \mathrm{C}$. The intestinal lumen is filled with standard Krebs buffer containing marker molecules via a syringe. The distal cannula is connected to a low pressure sensor (P). Contractility is recorded as pressure difference compared to a reference port and registered by Multiple Channel Registration computer-software.
$1.2 \mathrm{KH}_{2} \mathrm{PO}_{4}, 25 \mathrm{NaHCO}_{3}$ and 8.3 glucose. Each segment was directly cannulated with stainless-steel cannulas, mounted horizontally in a $5 \mathrm{ml}$ doublewalled perspex organ bath (Fig. 1). The organ baths, warmed to $37^{\circ} \mathrm{C}$, were filled with standard Krebs buffer and continuously gassed with carbogen $(95 \%$ $\mathrm{O}_{2}$ and $5 \% \mathrm{CO}_{2}$ ). The intestinal lumen was filled with Krebs buffer containing marker molecules; $0.25 \mu \mathrm{Ci} /$ $\mathrm{ml}^{3} \mathrm{H}$-mannitol (NEN Life Science Products, Hoofddorp, The Netherlands), with a specific activity of $22.4 \mathrm{Ci} / \mathrm{mmol}$ and $0.25 \mu \mathrm{Ci} / \mathrm{ml}^{14} \mathrm{C}$-PEG 400 (Amersham Life Science, 's-Hertogenbosch, The Netherlands), with a specific activity of $0.135 \mu \mathrm{Ci} / \mathrm{mol}$. The distal cannula was connected to a low pressure sensor (Dépex, De Bilt, The Netherlands), which measures pressure differences between a passive port, set at $15 \mathrm{mmHg}$ (registration range: $\pm 10 \mathrm{mmHg}$ ), and the intraluminal pressure of the intestinal segment. The signal was recorded by using Multiple Channel Registration (MCR) computer-software.

\section{Permeability measurement In vitro}

Permeability measurement started at $t=0$ by replacing the organ bath fluid with $5 \mathrm{ml}$ of fresh, carbogenated Krebs buffer. Every subsequent $5 \mathrm{~min}, 1 \mathrm{ml}$ samples were taken from the serosal reservoir for marker analysis, directly followed by exchange of the entire organ bath fluid. This procedure was continued for $55 \mathrm{~min}$. The samples were collected in $20 \mathrm{ml}$ Econo glass vials (Packard Instrument BV, Groningen, The Netherlands) and $7 \mathrm{ml}$ of scintillation fluid (Pico-Fluor 15; Packard Instrument BV, Groningen, The Netherlands) was added. Each vial was counted for radioactivity by $\beta$ liquid scintillation counting (1500 TRICARB Liquid Scintillation Analyzer; Packard Instrument BV, The Netherlands).

\section{Contractility measurement In vitro}

Running parallel with the permeability measurements, contractile activity was monitored by measuring intraluminal pressure $(\mathrm{mmHg})$ in each segment. At $t=25,30$ and $35 \mathrm{~min}$, smooth muscle relaxation was induced by adding a single dose of $50 \mu \mathrm{l}$ nitroprusside $\left(0.1 \mathrm{M}\right.$; final concentration $\left.10^{-3} \mathrm{M}\right)$ to the organ bath directly after buffer exchange. At $t=40,45$ and $50 \mathrm{~min}$ smooth muscle contraction was induced following the same procedure with a single dose of $50 \mu \mathrm{l}$ carbachol $\left(0.1 \mathrm{M}\right.$; final concentration $\left.10^{-3} \mathrm{M}\right)$.

\section{Macroscopy and histology}

Upon sacrifice, the removed intestines were macroscopically examined. Signs of inflammation were scored. The macroscopic score ranged from $0-8$, which represents the sum of scores from 0 to 2 for weight gain, appearance, diarrhoea and occult blood. 
Table 1. Histologic grading of colitis

\begin{tabular}{lcl}
\hline Feature graded & Grade & Description \\
\hline Inflammation & 0 & None \\
& 1 & Mild \\
& 2 & Moderate \\
& 3 & Severe \\
Damage/necrosis & 0 & None \\
& 1 & Mild (superficial) \\
& 2 & Moderate (involving \\
& 3 & muscularis mucosa) \\
& & Severe (transmural, involving \\
& 3 & None \\
Regeneration & 2 & $\begin{array}{l}\text { Focal migration and mitotic } \\
\text { features }\end{array}$ \\
& 1 & Broad, multifocal re \\
& 0 & Cpithelialization \\
& 0 & \\
& &
\end{tabular}

Specimens of proximal, middle and distal colon were taken for histology. The sections were fixed in 3.6\% buffered formalin, $\mathrm{pH} 7$, and embedded in paraffin wax. Sections cut at $5-\mu \mathrm{m}$ thickness, and stained with haematoxylin and azafloxin were examined under a light microscope using a $40 \times$ magnification. A colitis activity score was used to score each section in a blind fashion based on the method of Dieleman et $a l^{13}$ and as detailed in Table 1 . The total histological activity score ranged from 0 to 9 , which represents the sum of scores from 0 to 3 for inflammation, damage/necrosis and regeneration.

\section{Cytokine bioassays}

Small tissue sections of proximal and distal colon were taken for determination of IFN- $\gamma, \mathrm{TNF}-\alpha$ and IL$1 \beta$ cytokine synthesis. After adding $1 \mathrm{ml}$ of standard Krebs buffer, the tissue was homogenized for $\pm 10 \mathrm{~s}$ using an Ultra-Turrax (Polytron, Switzerland). The suspension was centrifuged $\left(400 \times \boldsymbol{g}, 10 \mathrm{~min}, 4^{\circ} \mathrm{C}\right)$ and the supernatant was stored at $-20^{\circ} \mathrm{C}$ until analysis. The cytokine concentration in the supernatant was determined by means of ELISA and expressed in $\mathrm{pg} / \mathrm{mg}$ tissue.

For IFN- $\gamma$, a specific mouse IFN- $\gamma$ ELSA kit was obtained from HyCult biotechnology BV (Uden, The Netherlands). Microplates pre-coated with monoclonal antibody specific for mouse IFN- $\gamma$ were incubated with $150 \mu \mathrm{l}$ sample or standard for $1 \mathrm{~h}$ at $37^{\circ} \mathrm{C}$. After three washing steps, $100 \mu \mathrm{l}$ of biotinylated antibody reagent mixed with streptavidin conjugate was added. Microplates were incubated for $1 \mathrm{~h}$ at $37^{\circ} \mathrm{C}$. After three times washing, $100 \mu \mathrm{l}$ para-nitrophenyl-phosphate (PNPP) substrate solution was added to the wells. Microplates were developed at $37^{\circ} \mathrm{C}$ for 30 min in the dark. To stop the enzymatic reaction $30 \mu \mathrm{l} \mathrm{NaOH}(3 \mathrm{M})$ was added. The optical density was measured spectrophotometrically at $450 \mathrm{~nm}$ using a
Microplate Reader (model 3550, Bio-Rad Laboratories, Richmond, USA). The detection range was between 175 and $7000 \mathrm{pg} / \mathrm{ml}$. For the assay ofTNF- $\alpha$, a specific mouse TNF- $\alpha$ ELISA kit was obtained from Biotrak (Amersham Life Science, UK). Microplates pre-coated with a solid phase monoclonal antibody specific for mouse TNF- $\alpha$ were incubated with $50 \mu$ sample or standard along with $50 \mu \mathrm{l}$ biotinylated antibody reagent for $2 \mathrm{~h}$ at room temperature. After washing five times to remove unbound sample proteins and biotinylated antibody, $100 \mu \mathrm{l}$ of streptavidin conjugated to horseradish peroxidase (HRP) was added to the wells. Microplates were incubated for $30 \mathrm{~min}$ at room temperature and washed five times. Hereafter, $100 \mu \mathrm{l}$ of TMB substrate solution was added. The microplates were developed at room temperature for $30 \mathrm{~min}$ in the dark. To stop the enzymatic reaction $100 \mu \mathrm{l}$ sulphuric acid $(0.18 \mathrm{M})$ was added to the wells. The optical density of each well was determined spectrophotometrically by using the Microplate Reader at $450 \mathrm{~nm}$. The detection range was between 50 and $2450 \mathrm{pg} / \mathrm{ml}$.

IL-1 $\beta$ was determined by using a high sensitivity IL$1 \beta$ assay from Biotrak (Amersham Life Science, UK). Microplates pre-coated with a solid phase monoclonal antibody specific for mouse IL-1 $\beta$ were incubated with $50 \mu \mathrm{l}$ sample or standard along with $50 \mu \mathrm{l}$ biotinylated antibody reagent for $2 \mathrm{~h}$ at room temperature. After three washing steps, $100 \mu \mathrm{l}$ of streptavidin-HRP conjugate was added to the wells. The microplates were incubated for $30 \mathrm{~min}$ at room te mperature. After three washing steps, $100 \mu \mathrm{l}$ of TMB substrate solution was added. Microplate development and measurement was similar to the TNF- $\alpha$ assay. The detection range was between 15.6 and $1000 \mathrm{pg} / \mathrm{ml}$.

\section{Statistical analysis}

Data are presented as means (SEM). The statistical significance of differences was determined by using the Mann-Whitney ranking test. $P<0.05$ was considered statistically significant.

\section{Results}

All mice developed a mild colitis after drinking 10\% DSS for 8 days. The macroscopic score for appearance, diarrhoea, occult blood and weight gain was significant increased $(P<0.01)$ in $10 \%$ DSS-treated animals compared with controls (Table 2). Microscopic examination of tissue from different intestinal regions showed a significantly increased score $(P$ $<0.05$ ) in proximal and distal colon segments of $10 \%$ DSS-treated animals versus controls.

The production of IFN- $\gamma$ in inflamed proximal and distal colon tissue was significant increased $(P<0.05)$ compared with controls. IL-1 $\beta$ levels in inflamed 
Table 2. Experimentally induced colitis by $10 \%$ DSS administration to BALB/c mice. The degree of inflammation determined by macroscopic scoring and histology for proximal, middle and distal colon segments of control $(n=5)$ and $10 \%$ DSS treated mice $(n=7)$

\begin{tabular}{|c|c|c|c|c|}
\hline \multirow[t]{2}{*}{ Group } & \multirow[t]{2}{*}{ Macroscopic score } & \multicolumn{3}{|c|}{ Microscopic score } \\
\hline & & Proximal & Middle & Distal \\
\hline $\begin{array}{l}\text { Control } \\
10 \% \text { DSS }\end{array}$ & $\begin{array}{l}0.4(0.3) \\
5.6(0.6)^{*}\end{array}$ & $\begin{array}{l}4.0(0.6) \\
6.4(0.6) * *\end{array}$ & $\begin{array}{l}3.0(0.9) \\
5.7(0.7)\end{array}$ & $\begin{array}{l}3.4(1.2) \\
6.4(0.5)^{* *}\end{array}$ \\
\hline
\end{tabular}

*Significantly different $(P<0.05)$ from control. ${ }^{*}$ Significantly different $(P<0.01)$ from control. Results are shown as mean score $(\mathrm{SEM})$.

Table 3. Experimentally induced colitis by $10 \%$ DSS administration to BALB/c mice. IFN- $\gamma$ and IL- $1 \beta$ levels in proximal, middle and distal colon segments of control $(\boldsymbol{n}=5)$ and $10 \%$ DSS treated mice $(\boldsymbol{n}=7)$

\begin{tabular}{lcccc}
\hline Segment & \multicolumn{2}{c}{$[\mathrm{IFN}-\gamma](\mathrm{pg} / \mathrm{mg}$ tissue) } & \multicolumn{1}{c}{$[\mathrm{IL}-1 \beta](\mathrm{pg} / \mathrm{mg}$ tissue) } \\
\cline { 2 - 3 } & Control & $10 \%$ DSS & Control & $10 \%$ DSS \\
\hline Proximal & $2.7(1.8)$ & $27.2^{*}(7.0)$ & $0.2(0.2)$ & $1.5(0.4)$ \\
Middle & $1.7(1.0)$ & $12.5(4.4)$ & $3.7(3.3)$ & $2.1(0.8)$ \\
Distal & 0 & $37.2^{*}(27.7)$ & $2.0(1.0)$ & $2.4(0.8)$ \\
\hline
\end{tabular}

*Significantly different $(P<0.05)$ from control. Results are shown as mean (SEM).

proximal and distal colon were raised, but not significantly different from controls (Table 3). TNF- $\alpha$ levels were under detection limit in intestinal tissue of both $10 \%$ DSS-treated and control animals (data not shown).

Passage of the marker molecules, from the luminal to the serosal side, was reproducible measured with the in vitro organ bath method. Figure 2 shows representative permeation profiles of a $10 \%$ DSS treated (B) and control (A) animal. Regional differences in permeability were observed. Distal colon segments were less permeable to ${ }^{3} \mathrm{H}$-mannitol and ${ }^{14}$ C-PEG 400 molecules compared with proximal colon and ileum in both groups. Exposure to 10\% DSS-induced enhanced permeability in the ileum segment, but did not alter permeability in the inflamed proximal and distal regions. The intestinal segments showed a higher passage of ${ }^{3} \mathrm{H}$-mannitol than of ${ }^{14}$ C-PEG 400 molecules in both groups. Simultaneously with permeability measurement, contractile activity was monitored in time (Fig. 3). Smooth muscle contraction is observed as an increase of intraluminal pressure, while relaxation of the smooth muscles was reflected by a decline in pressure. Periodic buffer exchange caused a revival of smooth muscle activity in proximal and distal colon segments, but this phenomenon was not observed in the ileum. Ileum intraluminal pressure diminished during the experiments possibly due to the large relaxing properties of the smooth muscles in these
(A)

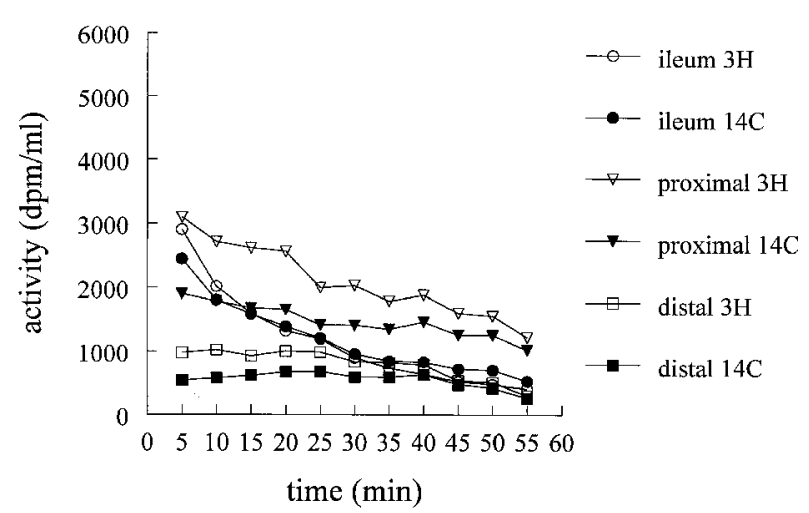

(B)

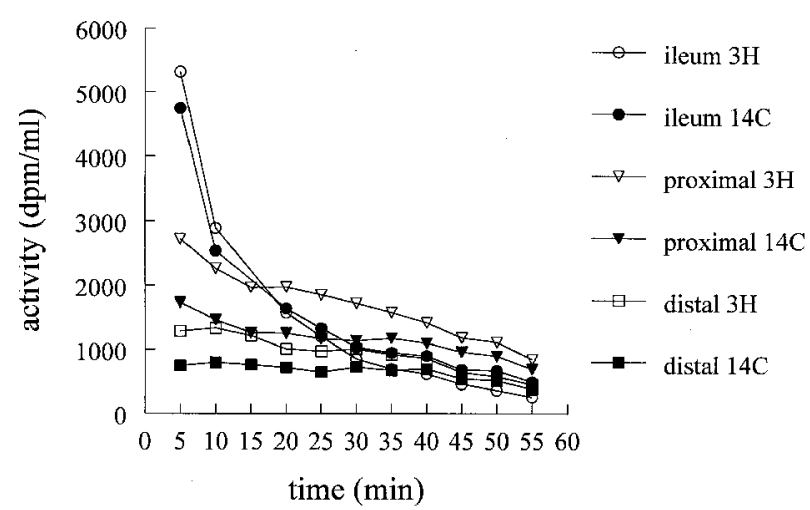

FIG. 2. Permeability monitored with ${ }^{3} \mathrm{H}$-mannitol $(3 \mathrm{H})$ and ${ }^{14} \mathrm{C}-\mathrm{PEG} 400(14 \mathrm{C})$ from luminal towards serosal side in different intestinal segments of a control (A) and 10\% DSS-treated mouse (B). 


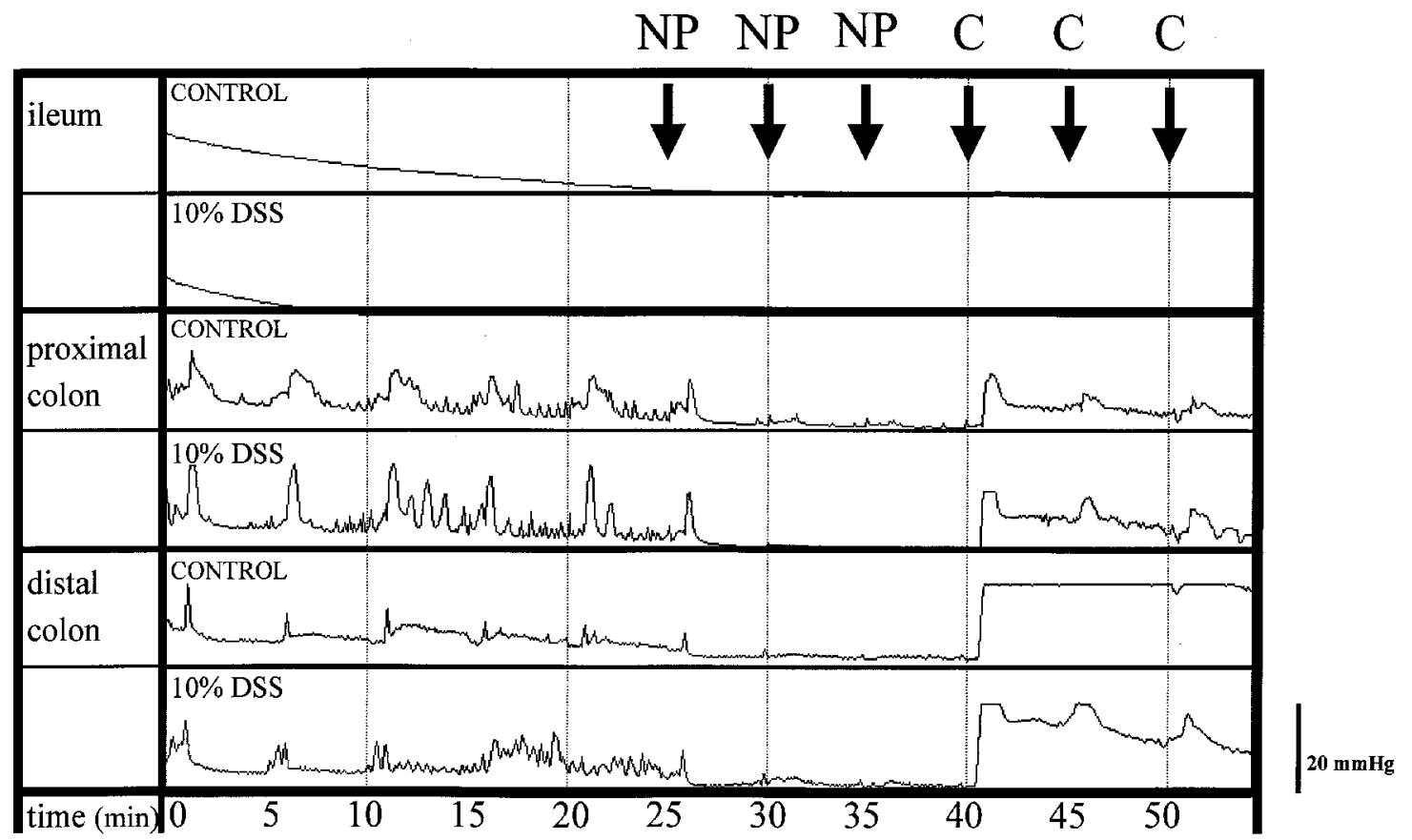

FIG. 3. Contractility, simultaneously measured with permeability (see Fig. 2) and serosal influenced by nitroprusside (NP) and carbachol (C) at various time points.

segments. Serosal additions of sodium nitroprusside induced a rapid decrease in smooth muscle activity, while repeated addition of carbachol resulted in a sustained smooth muscle contraction. Any effect of these pharmacologically induced contractile alterations on changes in intestinal permeability could not be observed.

\section{Discussion}

No previous studies have been able to measure permeability and contractility simultaneously in intestinal segments. We developed a new in vitro organ bath method in which reliable data were obtained in a physiological set-up. Intestinal permeability was measured with ${ }^{3} \mathrm{H}$-mannitol and ${ }^{14} \mathrm{C}-\mathrm{PEG} 400$ molecules, while smooth muscle contractility was online monitored by registration of intraluminal pressure.

Okayasu et al. ${ }^{14}$ developed a new experimental model for ulcerative colitis in mice. In our hands the applied animal model in which $10 \%$ DSS was administered via the drinking water to $\mathrm{BALB} / \mathrm{c}$ mice for 8 days, induced a reproducible mild colitis. Macroscopic signs of inflammation were reflected by diarrhoea, occult blood and loss of body weight. Contrary to the results of Okayasu et al. ${ }^{14}$ not only the distal colon was affected, but also proximal colon was significantly more inflamed in 10\% DSS treated mice. This may be caused by the difference in molecular weight of the administered DSS. In the present study dextran with a molecular weight of $>500000$ was used, while in the experiments of Okayasu et al. ${ }^{14}$ a dextran fraction with a molecular weight of 54000 was used to induce colitis.

After 8 days of $10 \%$ DSS administration IFN- $\gamma$ proinflammatory cytokine levels were significantly increased in proximal and distal colon segments. IL$1 \beta$ levels were also raised in these sections, but not significantly different from controls. Besides, TNF- $\alpha$ levels were undetectable in colonic tissue on day 8 . These results confirmed observations of van Dijk et $a l .{ }^{15}$ who found that IL-1 $\beta$ and TNF- $\alpha$ cytokines were detectable at peak levels on day 2 in 10\% DSS-treated $\mathrm{BALB} / \mathrm{c}$ mice and were subsequently dow nregulated thereafter.

Despite the significant increased degree of inflammation in proximal and distal colon segments, no difference in permeability to ${ }^{3} \mathrm{H}$-mannitol or ${ }^{14} \mathrm{C}-\mathrm{PEG}$ 400 molecules was observed. According to Hollander ${ }^{8}$ intestinal permeability of water-soluble compounds is dependent on the specific size of the marker molecules based on the hypothesis of tight junctional differences between intestinal villi and crypts. It was proposed that smaller and more resistant tight junctions at the tips of villi can be penetrated by smaller compounds. Larger compounds (around $10 \AA$ ) can only penetrate the crypt tight junctions where access from the lumen is more limited. Mannitol and PEG 400 are permeability markers of nearly equal size (6.7 and $5.3 \AA$ respectively). The permeation route of mannitol is proposed to be paracellular. The pathway of PEG 400 is not so clearly defined and is possibly paracellular and/or transcellular. ${ }^{9}$ Our results showed nearly identical permeation profiles for both marker molecules. Mannitol crossed the intestinal barrier in slightly larger amounts compared with PEG 400, 
resulting in mannitol/PEG 400 permeation ratios $\approx 1.3$ (data not shown). To discriminate between the two proposed tight junctional permeability routes, mannitol or PEG 400 and a larger marker molecule should be used in forthcoming experiments.

In addition, no effect of the pharmacological altered intraluminal pressure was seen on the permeation profiles. Sodium nitroprusside, a nitric oxidedonor inducing smooth muscle relaxation via cellular increased cGMP levels and carbachol known as a muscarinic agonist inducing smooth muscle contraction were possibly not able to alter intestinal permeability. Other pathways, like $5-\mathrm{HT}_{3}$ receptor agonists, triggering the fast opening of cation selective channels to induce contraction and for instance salbutamol as a selective $\beta_{2}$-receptor agonist inducing relaxation should be investigated.

In summary, we developed a new operational in vitro organ bath method in which simultaneous measurement of intestinal permeability and contractility in a physiological set-up is possible. However, despite the significantly enhanced degree of intestinal inflammation, altered permeability and contractility was not demonstrated, nor correlated in this model of experimentally induced colitis in mice. Further validation of this method is recommended.

\section{References}

1. Travis S, Menzies I. Intestinal permeability: functional assessment and significance. Clin Sci 1992; 82: 471-488.

2. Collins SM. The immunomodulation of enteric neuromuscular function: implications for motility and inflammatory disorders. Gastroenterology 1996; 111 : 1683-1699.
3. Jenkins RT, Ramage JK, Jones DB, Collins SM, Goodacre RL, Hunt RH Small bowel and colonic permeability to ${ }^{51} \mathrm{Cr}$-EDTA in patients with active inflammatory bowel disease. Clin Invest Med 1988; 11: $151-155$.

4. Reddy SN, Bazzocchi G, Chan S, Akashi K, Villanueva-Meyer J, Yanni G, Mena I, Snape WJ. Colonic motility and transit in health and ulcerative colitis. Gastroenterology 1991; 101: 1289-1297.

5. Peeters M, Hiele M, Ghoos Y, Huysmans V, Geboes K, Vantrappen G, Rutgeerts P. Test conditions greatly influence permeation of water soluble molecules through the intestinal mucosa: need for standardisation. Gut 1994; 35: 1404-1408.

6. Blomquist L, Bark T, Hedenborg G, Svenberg T, Norman A. Comparison between the lactulose/mannitol and ${ }^{51} \mathrm{Cr}$-ethylenediaminetetraacetic acid $/{ }^{14} \mathrm{C}$-mannitol methods for intestinal permeability. Scand J Gastroenterol 1993; 28: 274-280.

7. Bjarnason I, O'Morain C, Levi AJ, Peters TJ. Absorption of ${ }^{51}$ Chromiumlabeled ethylenediaminetetraacetate in inflammatory bowel disease. Gastroenterology 1983; 85: 318-322.

8. Hollander D. The intestinal permeability barrier. A hypothesis as to its regulation and involvement in Crohn's disease. Scand J Gastroenterol 1992; 27: 721-726.

9. Bjarnason I, Macpherson A, Hollander D. Intestinal permeability: an overview. Gastroenterology 1995; 108: 1566-1581.

10. Bijlsma PB, Peeters RA, Groot JA, Dekker PR, Taminiau JAJM, van der Meer $R$ Differential in vivo and in vitro intestinal permeability to lactulose and mannitol in animals and humans: a hypothesis. Gastroentero logy 1995; 108: 687-696.

11. Meyers BS, Dempsey DT, Yasar S, Martin JS, Parkman HP, Ryan JP. Acute experimental distal colitis alters colonic transit in rats. J Surg Res 1997; 69: 107-112.

12. Krugliak P, Hollander D, Schlaepfer CC, Nguyen H, Ma TY. Mechanisms and sites of mannitol permeability of small and large intestine in the rat. Dig Dis Sci 1994; 39: 796-801.

13. Dieleman LA, Ridwan BU, Tennyson GS, Beagley KW, Bucy RP, Elson CO. Dextran sulfate sodium-induced colitis occurs in severe combined immunodeficient mice. Gastroenterology 1994; 107: 1643-1652.

14. Okayasu I, Hatakeyama S, Yamada M, Ohkusa T, Inagaki Y, Nakaya R. A novel method in the induction of reliable experimental acute and chronic ulcerative colitis in mice. Gastroenterology 1990; 98: 694-702.

15. van Dijk APM, Keuskamp ZJ, Wilson JHP, Zijlstra FJ. Sequential release of cytokines, lipid mediators and nitric oxide in experimental colitis. Mediators Inflamm 1995; 4: 186-190.

\section{Received 16 March 1998;} accepted 19 March 1998 


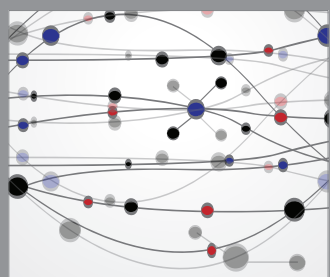

The Scientific World Journal
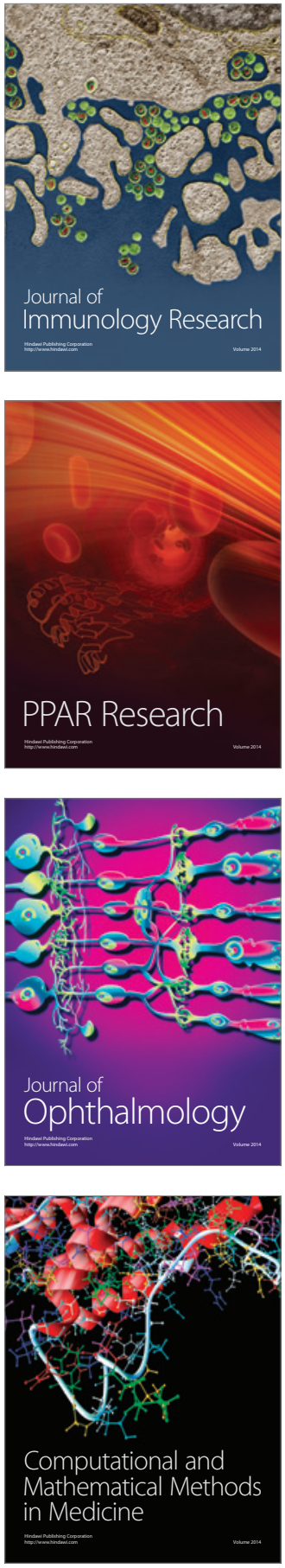

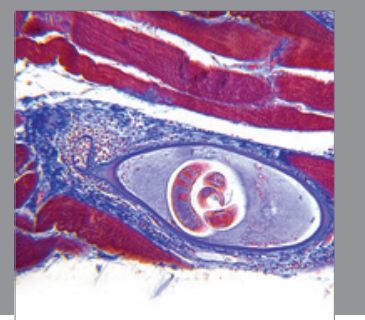

Gastroenterology

Research and Practice
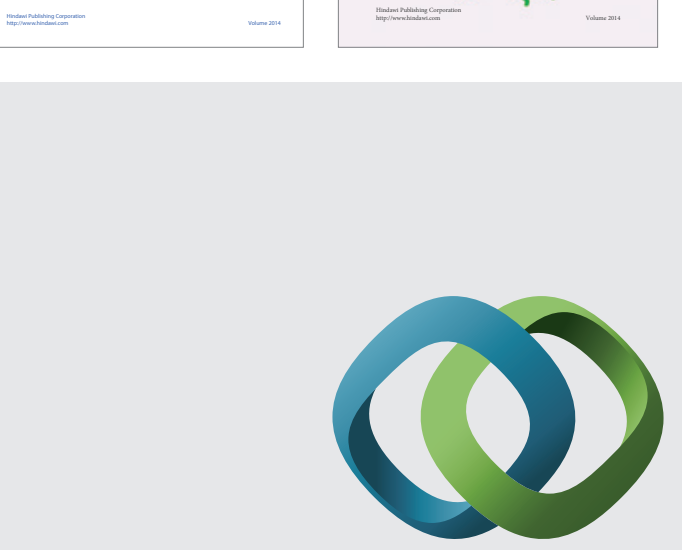

\section{Hindawi}

Submit your manuscripts at

http://www.hindawi.com
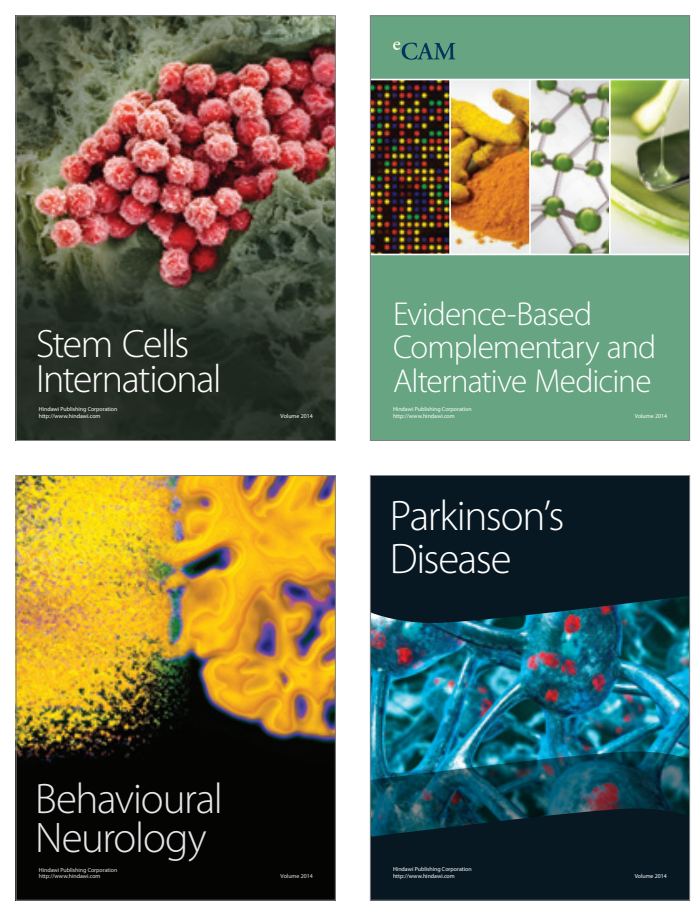

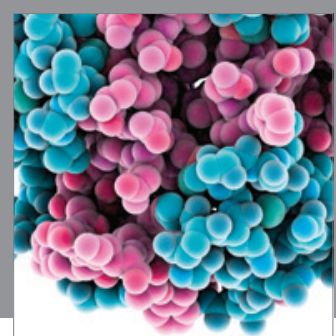

Journal of
Diabetes Research

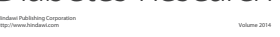

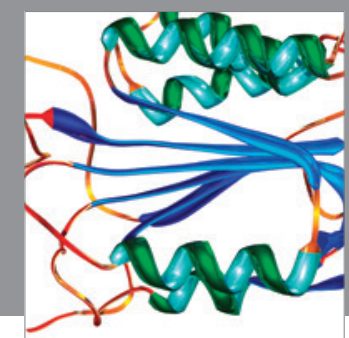

Disease Markers
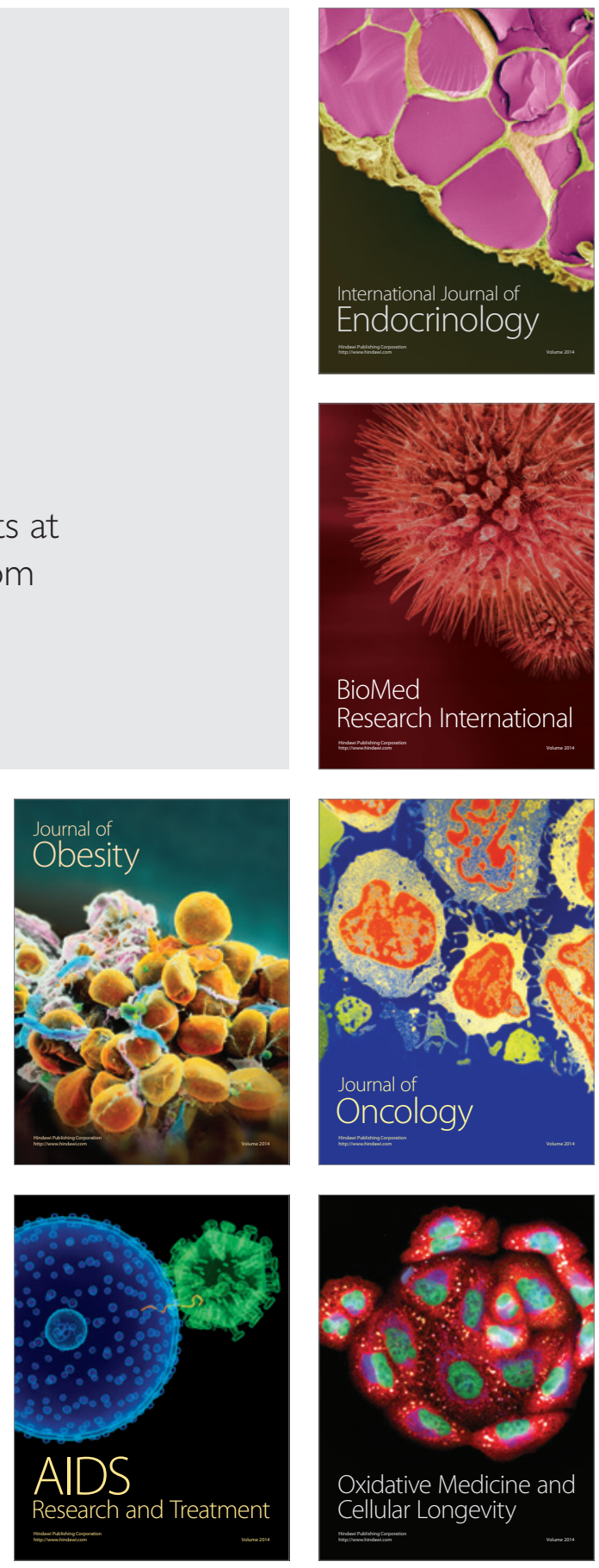